\title{
Policy and Regulation of Energy Transition
}

\author{
Karolina Daszkiewicz
}

\section{Overview and Background}

The world is at a turning point for what concerns energy trends. At a first glance, one can say that almost nothing happened over the last two decades: the share of fossil fuels in the overall global energy mix remained constant, at around $80 \%$. However, this global number hides many different important energy trends: the rise of China, to become the largest energy consumer of the world, mainly fuelled by coal and oil growth; shale oil and gas reshaping not only the consumption in the United States, but also shifting historical importers/exporter balance; the start of the next new energy giants: India, South East Asia and Africa.

On the other side, we have been seeing clear signals of the will of many governments to steer away from fossil fuels and to move towards a clean energy future. The implementation of vehicles standards for cars, energy efficiency labelling for appliances and support for renewables technologies are strong examples of pivotal policies that have been implemented over the recent decades with climate and sustainability angles, changing the way that we consume and produce energy. This resulted in the stall of the growth of energy-related $\mathrm{CO}_{2}$ emissions for several years.

But despite these encouraging signals, the $\mathrm{CO}_{2}$ emissions grew again in 2018, and we are far from achieving, and even being on the right track with the goals that most governments of the world agreed upon at the UNFCCC's conference of parties 21 (COP21), held in Paris in 2015. COP21 was a turning point, but countries' actions need to be stepped-up. As shown in the International Energy Agency's World Energy Outlook 2019, the gap between the efforts currently envisaged and the Paris Agreement pledges is huge. This can — and must-be filled by a series of actions that requires a series of actions and policies to be put in place.

\footnotetext{
K. Daszkiewicz $(\varangle)$

Energy Policies and Markets Expert, Paris, France

e-mail: daszkiewicz.karolina@gmail.com
} 
Many technologies and decarbonisation options are available, and it is up to each country to choose the best combination for them. Nevertheless, many areas still lag behind: removing the barriers that prevent the realisation of the huge energy efficiency potential, continuing the increasing deployment of renewable technologies in all sectors, supporting carbon, capture, utilisation and storage (CCUS) and place of nuclear technologies in the mix, creating the right conditions for these investments to be forthcoming are among some of the key policies that will need to be stepped-up in ambition over the next years.

This chapter is to outline the evolution of policies and regulations driving the energy transition with a focus on renewable energy technologies and energy efficiency.

\section{Policy Classification}

Countries have a range of policies and measures at their disposal to influence the deployment of renewables and energy efficiency improvements. These policies are multiple, ranging from tax benefits or waivers to capital grants, measures rewarding heat or power generation, self-consumption, or energy efficiency codes and mandates and many other tools.

Various energy strategies, targets and the majority of the policies aiming at decreasing investment costs can be used to trigger the deployment of renewables in all sectors-electricity, transport or heating and cooling. However, these policy tools can be adjusted and applied to incentivise improvements in the energy efficiency area. Price-finding mechanisms (e.g. auctions or administratively set tariffs) are mostly applicable to power generating renewables.

The below Table 1 attempts to group these policy tools and measures into overarching policy categories, enlists policy types, and track, if adjusted accordingly, the applicability of these tools across renewable sectors and the energy efficiency, provided necessary adjustments were implemented. Due to the breadth and depth of policy forms available, the below classification is not exhaustive.

Other approaches to classification of the policy types can be applied by sorting them from the angle of project size or purpose (electricity sector). Categorising policies per their exposure to market forces could be another approach (IRENA, IEA and REN21 2018).

In this chapter, only a few of the above-enlisted policy types will be explained in detail, in particular the ones that are responsible for bringing online the most significant shares of new capacities or particular relevance for either renewables or energy efficiency. 
Table 1 Policy classification and applicability to renewables and energy efficiency areas

\begin{tabular}{|c|c|c|c|c|c|}
\hline \multirow[t]{3}{*}{ Policy category } & \multirow[t]{3}{*}{ Policy type } & \multicolumn{4}{|c|}{ Applicability } \\
\hline & & \multicolumn{3}{|c|}{ Renewables } & \multirow[t]{2}{*}{ Energy efficiency } \\
\hline & & Power & $\mathrm{H} \& \mathrm{C}$ & $\mathrm{T}$ & \\
\hline \multirow{3}{*}{$\begin{array}{l}\text { Targets setting and } \\
\text { strategic planning }\end{array}$} & Energy strategies & $\sqrt{ }$ & $\sqrt{ }$ & $\sqrt{ }$ & $\sqrt{ }$ \\
\hline & Action plans & $\sqrt{ }$ & $\sqrt{ }$ & $\sqrt{ }$ & $\sqrt{ }$ \\
\hline & Targets & $\sqrt{ }$ & $\sqrt{ }$ & $\sqrt{ }$ & $\sqrt{ }$ \\
\hline \multirow{7}{*}{$\begin{array}{l}\text { Policies targeting } \\
\text { upfront investment } \\
\text { costs }\end{array}$} & Grants & $\sqrt{ }$ & $\sqrt{ }$ & & $\sqrt{ }$ \\
\hline & Rebates & $\sqrt{ }$ & $\sqrt{ }$ & & $\sqrt{ }$ \\
\hline & Soft loans & $\sqrt{ }$ & $\sqrt{ }$ & & $\sqrt{ }$ \\
\hline & Tax benefits & $\sqrt{ }$ & $\sqrt{ }$ & $\sqrt{ }$ & $\sqrt{ }$ \\
\hline & Tax waivers & $\sqrt{ }$ & $\sqrt{ }$ & $\sqrt{ }$ & $\sqrt{ }$ \\
\hline & $\begin{array}{l}\text { Depreciation tax } \\
\text { benefit }\end{array}$ & $\sqrt{ }$ & & & \\
\hline & Generation tax benefit & $\sqrt{ }$ & & & \\
\hline \multirow{7}{*}{$\begin{array}{l}\text { Policies targeting } \\
\text { energy generation }\end{array}$} & Feed-in tariffs (FITs) & $\sqrt{ }$ & $\sqrt{ }$ & & \\
\hline & $\begin{array}{l}\text { Feed-in premiums } \\
\text { (FIPs) }\end{array}$ & $\sqrt{ }$ & $\sqrt{ }$ & & \\
\hline & Auctions & $\sqrt{ }$ & & & \\
\hline & Tenders & $\sqrt{ }$ & & & \\
\hline & $\begin{array}{l}\text { Contract for difference } \\
\text { (CfD) }\end{array}$ & $\sqrt{ }$ & & & \\
\hline & Certificates & $\sqrt{ }$ & $\sqrt{ }$ & & $\sqrt{ }$ \\
\hline & $\begin{array}{l}\text { Policies for } \\
\text { self-generation, } \\
\text { self-consumption and } \\
\text { sell of electricity to the } \\
\text { grid }\end{array}$ & $\sqrt{ }$ & & & \\
\hline \multirow[t]{6}{*}{ Regulatory } & $\begin{array}{l}\text { Rules on connection } \\
\text { and dispatch }\end{array}$ & $\sqrt{ }$ & & & \\
\hline & $\begin{array}{l}\text { Mandates and } \\
\text { obligations }\end{array}$ & $\sqrt{ }$ & $\sqrt{ }$ & $\sqrt{ }$ & $\sqrt{ }$ \\
\hline & Standards & & $\sqrt{ }$ & $\sqrt{ }$ & $\sqrt{ }$ \\
\hline & Labels & & & & $\sqrt{ }$ \\
\hline & Portfolio Standards & $\sqrt{ }$ & $\sqrt{ }$ & & $\sqrt{ }$ \\
\hline & $\begin{array}{l}\text { Regulatory } \\
\text { environment not } \\
\text { prohibiting or } \\
\text { permitting corporate } \\
\text { PPAs }\end{array}$ & $\sqrt{ }$ & & & \\
\hline
\end{tabular}


Table 1 (continued)

\begin{tabular}{|c|c|c|c|c|c|}
\hline \multirow[t]{3}{*}{ Policy category } & \multirow[t]{3}{*}{ Policy type } & \multicolumn{4}{|c|}{ Applicability } \\
\hline & & \multicolumn{3}{|c|}{ Renewables } & \multirow[t]{2}{*}{ Energy efficiency } \\
\hline & & Power & $\mathrm{H} \& \mathrm{C}$ & $\mathrm{T}$ & \\
\hline \multirow[t]{3}{*}{ Other policies } & $\begin{array}{l}\text { Education and } \\
\text { information } \\
\text { dissemination }\end{array}$ & $\sqrt{ }$ & $\sqrt{ }$ & $\sqrt{ }$ & $\sqrt{ }$ \\
\hline & Training & $\sqrt{ }$ & $\sqrt{ }$ & $\sqrt{ }$ & $\sqrt{ }$ \\
\hline & $\begin{array}{l}\text { Research, } \\
\text { Development and } \\
\text { Deployment } \\
\text { programmes }\end{array}$ & $\sqrt{ }$ & $\sqrt{ }$ & $\sqrt{ }$ & $\sqrt{ }$ \\
\hline
\end{tabular}

Note: $\mathrm{H} \& \mathrm{C}=$ Heating and Cooling, $\mathrm{T}=$ Transport sectors

\section{Renewable Energy}

\subsection{Renewable Energy Policy Evolution and Geographical Spread}

The deployment of wind and solar photovoltaics (PV) technologies progressed at a rapid pace over the past two decades growing from a nascent level and from few locations. While renewables in power sector made an impressive progression, renewables in transport and heating sectors developed at a slower pace lagging behind which is closely related to the level and effectiveness of corresponding policy adoption.

In 2000, only few countries had in place policies directly targeting renewable power technologies, with various rates of success. In 2010, already 45 countries had a renewable target in place and around 60 countries had some form of a measure remunerating directly renewable power generation gaining experience with feed-in tariffs. By 2017, the number of countries that adopted renewables target had grown to almost 180, of which two-thirds had in place policies incentivising renewable power generation. Robust policy adoption corresponded directly with increasing annual net additions commissioned in countries across all regions.

Countries aiming to support renewables in transport sector mainly use various forms of biofuel blending mandates. In 2010, only approximately 30 countries had mandates in place. By 2017, this number tripled. However, majority of the mandates require relatively low biofuel blending shares and countries' limited efforts to enforce them on the part of governments result in slower progression of renewables in the transport energy consumption.

At the same time, opportunities for the deployment of renewables in heating and cooling sector are vast as this is the largest end-use sector, accounting for more than half of total worldwide final energy consumption. However, renewable energy policy adoption visibly lags behind fort this sector. In 2010, only 13 countries had in place a renewable heat mandate with the majority located in Europe. By 2017, the number of 
countries with some form of a renewable heat mandate increased only to 22. European countries continued to lead policy adoption in this sector driven by obligations under the EU Renewable Energy Directive with mandatory 2020 renewable targets (IEA 2018).

Over time, renewable energy policies evolved, morphed and diversified in their structure, in particular policies targeting renewable electricity.

\subsubsection{Targets}

Target setting (in absolute or share levels) is often country's first step in strategy and policymaking for renewables deployment. Targets provide a clear objective where a country, region or city aims to get in terms of renewables deployment and may or may not consider how renewables will interplay with other energy technologies in the future energy mix and over a clearly defined period. They are often accompanied by a roadmap or an action plan in which the country enlists the measures it intends to use in order to achieve set objectives, translating targets into concrete steps and actions. This step is usually followed up by a secondary legislation, which adopts rules and renewable energy measures such as fiscal or financial policies, measures setting tariffs for renewable power generation, premiums or programmes supporting self-consumption.

In order to set ambitious yet achievable targets, target adoption is usually preempted by a series of studies and consultations such as resource availability study, technical potential and cost competitiveness assessments, grid integration and evolution of energy demand. These give a clear set of information on which targets can be set in an informed way by a country (IRENA 2015).

Renewable energy targets have four major characteristics:

1. strength and obligation status;

2. structure and scope;

3. time scale;

4. context.

The first element defines whether a target is of voluntary or of a binding nature. For the target to be legally binding it must be adopted into the national law. The target can be embodied in the overall energy act or adopted by a specific renewable energy legislation. Targets can also be set in the form of renewable obligation (RO), Fuel Mandate or renewable portfolio standard (RPS) that are adopted as secondary level laws and are renewable energy mechanisms per se.

Example of a legally binding target is the European Union's 2020 renewable target adopted in 2009 by Renewable Energy Directive 2009/28/EC. This target is binding for the overall of the European Union but it is also accompanied by legally binding country-level targets, which are expressed in a share of renewable energy consumed in country's total energy consumption in 2020. These targets are further split into sector-level objectives that are non-binding but are of an indicative nature on how countries intend to achieve their overall targets. Nonfulfillment of the overall targets 
is to be penalised with financial fines placed on member countries by the European Union.

Voluntary targets are not incorporated into national body of law but noted in various policies and strategies, and they do not entail financial burdens or fines.

Renewable energy targets can take a wide range of forms and structures. The first tier target is an overall target, applicable to country's entire energy mix (as before mentioned EU target). The second tier targets refer to a specific sector such as electricity, transport or heating and cooling sectors. The third granularity level of the target specifies if the target is technology-neutral or split into specific technology targets (separate target for solar PV capacity to be reached, wind, etc.). While a technology-neutral target allows markets to decide on the most cost-effective renewable technology option to be used in order to meet the target, it can also lead to overrepresentation of one technology on the market with the most mature technology dominating the deployment and preventing other technologies from maturing. There is a benefit in assuring deployment of a variety of technologies. Technology specific targets guarantee that technologies that are not yet fully mature will have their opportunity to develop within the country market.

While setting the target, a country should decide the metrics in which the target is expressed in and therefore chooses how the progression towards the target is to be measured and calculated. One of the most commonly used metrics by countries are either total primary energy supply (TPES) or total final energy consumption (TFEC). Targets can be also expressed as a share of energy demand or a specific amount of energy, power, heat or fuel delivered or consumed measured in a corresponding metric unit.

The third target element is its time scope. Typically targets are set for 10 or 15 years periods, however, many countries choose shorter horizons for their objectives. For example, China operates on the basis of carefully designed 5-Year Plans. Targets with horizons of 20 years and over are also practiced and are often accompanied by supporting mid-term targets.

Often, countries set renewable energy targets in a larger context of their overall energy and climate strategies. The EU 2020 and 2030 renewable targets are accompanied by the $\mathrm{CO}_{2}$ reduction and energy efficiency targets. Countries often embed renewable targets in their overall energy mix objectives that are increasingly supplemented by climate targets.

Target setting is an important process that should be done carefully and supported with various studies. Regardless of what approach is chosen for a target setting, tracking progression towards the set objectives is a fundamentally important part of the process. This requires for the policymakers and regulators to develop a clear and coherent monitoring process.

However, the stand-alone target is an orphaned ambition if not supplemented with an appropriate blend of policies and measures triggering renewables deployment and putting countries on the path to meet the set targets.

The above-explained target setting process refers mostly to setting tangible objectives in the renewables sector. However, it can be replicated and adjusted accordingly 
to setting objectives in the area of energy efficiency or any other part of the energy system.

\subsubsection{Fiscal and Financial Policies}

Most low-carbon technologies face high capital costs, and therefore the conditions for finding such capital and the financing conditions can play an essential role in the deployment of these technologies. Fiscal and financial policies generally aim at reducing upfront capital costs and providing cheaper and more affordable financing conditions to investors. These can take a wide range of forms such as capital grants and rebates, soft loans, tax discounts, tax waivers or other tax benefits. These measures are easy to adopt and are often the first type of renewable support in place. They can also be complemented by other policies and measures directly supporting renewable production. These measures are rarely stand-alone policies available in a country, although stand-alone tax benefits and waivers are adopted in developing countries where no other measures are yet implemented.

Fiscal and financial measures are easy to manage from an administrative side as they can be amended, adjusted or removed within regular budgetary work of the government. These measures can address any particular renewable energy technology and are applicable to any sector. Measures supporting renewables are often embedded into energy efficiency policies and support systems. These types of policies can be used in renewables as well as in the energy efficiency efforts across all sectors and users. Their characteristics and principles remain similar but the beneficiary changes accordingly to an envisaged effect the measure supposed to achieve.

\subsection{Renewable Electricity Policies}

Much of the renewables policies over the last two decades have been aiming at increasing installed capacity in the electricity sector. Renewable capacity more than tripled from $850 \mathrm{GW}$ in 2000 to $2500 \mathrm{GW}$ by the end of 2018, with more than $90 \%$ of this growth coming from hydro, wind and solar PV in almost equal shares. Hydropower was-and still is - the largest renewable power technology, both in terms of capacity and of electricity generation. For long, it has also been leading the annual additions of installed capacity. Nearly twenty years ago, total installed onshore wind capacity was less than $20 \mathrm{GW}$, offshore wind was an experimental technology with only demonstration projects in waters, and solar PV total capacity was standing at less than $1 \mathrm{GW}$.

Over the last two decades, wind and solar PV technologies experienced efficiency gains and large cost cuts. By 2018, solar PV additions grew to some $100 \mathrm{GW}$ level reaching total installed capacity of around $500 \mathrm{GW}$ and wind annual additions grew by $50 \mathrm{GW}$ reaching $565 \mathrm{GW}$ installed capacity. Hydropower was no longer a leading technology in terms of capacity additions, expanding by $20 \mathrm{GW}$ in 2018 ; half of these 
new projects came online in China, as majority of viable sites for large hydropower projects in the OECD countries have been already used (IEA 2019e).

In 2000, half of the global annual renewable capacity additions were commissioned in Europe. In 2018, renewables growth was spread across all regions with China accounting for $43 \%$ of the global growth and Europe delivering third-highest level of new projects after APAC region. Renewables for power generation are turning from an expensive possibility for few to a mainstream across the globe (IEA 2019e).

There is a strong link between pace of additions and renewable energy policy adoption. Knowing the evolution of policy types and history of policy adoption across regions and sectors is important to understand the success and failures that have been a part of renewables take off and allow to draw lessons for the future (IEA 2018).

\subsubsection{Evolution of Feed-in Tariffs and Feed-in Premiums}

Feed-in tariffs (FITs) are administratively set price tariffs for electricity generated by renewable energy technologies. Countries started using FITs in the late 1970s as an incentive tool, gaining policy expertise over time (NREL 2010). With that and growing maturity of renewable technologies paired with dropping costs, the FIT systems started being more complicated with tariffs tailored to technology, installation size, mounting system type and often location of the installation. Remuneration levels are set by countries' regulatory office, separated from the market forces. Tariffs are assigned in long-term power purchase agreements (PPAs) signed between the generator and the responsible energy regulatory body or the electricity offtaker.

FIT contracts durations are usually of 12-20 years, reaching up to a maximum of 30 years in rare cases. Initially, the duration of FITs was of the same length for all technologies and project sizes. However, similar to remuneration levels, countries started gradually to adjust contracts' lengths to technology life cycles and how fast developers would get the return on their investments. Ultimately, on average, FIT contracts' durations become shorter and shorter oscillating currently around 1015 years.

Initially used to support the deployment of all types and size renewable power stations, developed economies started limiting the use of FITs for renewables deployment in favour of other price-finding mechanisms. Conversely, in several developing countries FITs continue to be used, mostly for support of small installations for residential and commercial usage. They also continue to be an important mechanism for the deployments of all types and size of renewable installations in these countries, where access to financing instruments is more limited and investment is overall riskier.

One of the main limitations of FITs is the difficulty to accurately identify the correct level of remuneration for the amount of power generated, and to adjust it rapidly and in sync with the decrease of the technology costs. If the FIT is not sufficiently high, it will not trigger investors' interest, while if it is too high it will 
provide an excessive return on the investment, increasing the burden to electricity consumers or taxpayers. This second case can be exacerbated by the fact that, unless complemented with additional policies, there is no control on the volume of new capacity.

Feed-in premiums (FIP) are also set administratively, similar to feed-in-tariffs, but hold a greater exposure to electricity markets, as they are paid on top of the electricity price set by the market and collected by the generator. The overall remuneration of the project is therefore the sum of the electricity price received from the market and the FIP. The advantage of this mechanism is that generators are encouraged to react to the variation of electricity prices, while on the other side it increases their market exposure and therefore the risks associated to the project. FIPs can be set to remain constant over time regardless of the variation of the electricity price or sliding, with adjustments and eventual minimum and maximum levels. Similar to the FITs case, FIPs are contracted for long periods under PPAs.

Feed-in policies played a pivotal role in renewables deployment that was successfully adopted in Germany and later duplicated by many countries. In 2010, just over 50 countries had either a feed-in tariff or premium tariff systems in place, of which nearly half were European countries, followed by adoption in APAC region. By 2017, FITs or FIPs were in place in over 80 countries with Europe continuing to lead the adoption followed by APAC, Eurasia and other regions. The International Energy Agency reports that feed-in tariff and premium policies were the main policy bringing online around $80 \%$ of all commissioned utility-scale renewable projects over 2012-2017 period (IEA 2018). However, the policy paradigm shifted as renewables became more mature, and costs have experienced large cuts with countries turning towards auctions for price-finding mechanism for large-scale projects. Going forward, with China limiting its feed-in tariff policy, the IEA estimates that the feed-in mechanisms will drive around $40 \%$ of the global large-scale deployment over the next five years (2019-24) (IEA 2019e).

Administratively set tariffs are set to continue to play an important role for hydropower, concentrated solar panels (CSP), marine and geothermal technologies. Renewable auctions can drive the deployment, serving as a new go-to policy mechanism for large renewables, in particular for solar PV and wind projects. Nevertheless, countries start to increasingly use auction systems for awarding contracts to mid-size, or commercial size projects.

\subsubsection{Renewable Auctions}

Renewable energy auction is a selection process designed to procure new renewable electricity capacity (or generation volumes) competitively, in which a long-term PPA is granted to a qualified bidder based on a submitted financial offer, and in certain cases, additional criteria (e.g. the bidder's financial health, bank guarantees received, and previous experience in developing and operating renewable energy plants). 
Auctions are, in fact, a price-discovery tool that takes advantage of competitive forces, shifting the burden away from the administrator who is responsible for setting the suitable framework within which private sector bids for a price and project.

Auctions are an excellent mechanism for a renewable capacity volume-control; however, their design must be carefully tailored to each country's context, as any other policy mechanism, in order to be effective. Auction mechanism must be designed so to attract sufficiently large pool of competition, which ultimately leads to low price discovery. Additionally, auctions must be accompanied by rules preventing unsuitable developers from participating or winning the auction and failing to deliver the allotted production capacity.

Auctions can be either open to all renewable technologies, wherein all projects compete with one another, or limited to one specific technology, for example to solar PV. PPAs can then be structured to incentivise production in desired locations more than in others, or at certain times that are more valuable to the system.

In auctions, bidders are invited to compete for a portion of the capacity up for auction (the minimum capacity size is usually specified in the auction rules), while in tender processes bidders must bid on the entirety of the sought-after capacity.

Winning developers are granted long-term PPAs, usually of up to 20 or 25 years depending on the country, project and technology. In effect, auctions are a pricefinding mechanism for granting contracts similar to the way FITs and FIPs do. Renewable energy auctions are most suitable for procuring utility-scale projects. Large companies are most likely prone to participate, be eligible for participation and win the PPA contracts.

Set up of the auction system is difficult to cope with successfully by smaller companies to participate in, so there is a risk that competition will, in effect, be limited to several large players that will dominate the results and cut the smaller entities out of the market.

Selected project developer turn to financial institutions to secure loans. Once conditions of the loan are secured, the developer return to the relevant institution or the offtaker to sign the PPA. Time limits and penalties for late delivery of contracted projects are embedded in the PPA conditions.

In 2010 , less than 20 countries had a renewable auction mechanism in place with Europe leading the adoption (seven countries), followed shortly by five countries from Latin America region. By 2017, number of countries with auctions increased to 88 and overtook number of countries with feed-in mechanisms in place. Europe is no longer a region dominating auctions activity as countries of Latin America, Eurasia, Africa and APAC are very active in adoption and running consecutive auction rounds as well. Within the next five years, auctions are to drive the large-scale renewable deployment bringing around two-thirds of global capacity growth. Nearly all largescale renewable capacity to come online in Latin America is to come online winning bids in national auctions. In Europe, MENA and North America regions auctions are to drive around $70 \%$ of all renewable additions while in China and other Asia regions auctions are to drive just over half of the new deployment (IEA 2018).

Less developed regions, such as sub-Saharan Africa and Eurasia are to support the large renewables through a blend of feed-in tariffs and auctions policies 
as hydropower continue to be an important technology for new projects that are usually signed under administratively set tariffs, and non-hydropower renewables are still in early deployment levels and require strong policy framework (IEA 2019e).

Subsequently, annually awarded capacity volumes were increasing on an annual basis. In 2010, just under $3 \mathrm{GW}$ of capacity was awarded, with majority of contracts going to onshore wind projects in Brazil. By 2017, auctions around the world allotted contracts to projects corresponding to $28 \mathrm{GW}$ capacity to be commissioned across Latin America, APAC, Europe and North America regions. Nearly half of winning bids came from solar PV projects, followed by wind. In the first three quarters of 2019, a record of $40 \mathrm{GW}$ renewable capacity was awarded through auctions tipped by China running renewable capacity auctions for utility and commercial size solar PV projects and completing country's first offshore wind auction round.

All together, as of the third quarter of 2019, auctions globally allocated long-term PPAs to around $175 \mathrm{GW}$ of renewable capacity with the most recent wins to be commissioned by 2022.

Introducing factor of a strong competition pushed developers to drive cost cuts along the supply chain, in particular for solar PV and onshore wind technologies as they represent over $95 \%$ of the awarded capacity, with hydropower, bioenergy, geothermal and CSP accounting for the remaining portion (IEA 2019f). Capacityweighted average auction prices for utility-scale solar PV projects declined from almost USD 160/MWh for those projects commissioned in 2014 to around USD 70/MWh for projects commissioned in 2018. Prices for projects selected in the 2019 auctions noted further decline with contracts awarded at USD 40/MWh. These projects are estimated to come online in 2022 given the usual project lead times for this technology and clauses written in the auction guidelines (IEA 2019e).

Average auction prices dropped for onshore wind fell from USD 65/MWh for projects commissioned in 2014 to around USD 56/MWh for projects coming online in 2018. Given the 2019 auction results, some projects to come online in 2022 will sell their generated electricity just below USD 40/MWh (IEA 2019e).

Going forward, auctions are expected to increasingly drive larger shares of annual additions as a tool that is able to secure attractive prices for new capacities, drive innovation and more policy know-how from various country setups are emerging. Increasingly, developing countries in Eurasia and sub-Saharan Africa are introducing auctions, often with a support from international financial agencies such as the World Bank, EBRD and other regionally relevant institutions that are able to assist with policymaking and often provide funds for soft financing for the initial auction rounds.

However, in countries where renewable energy policies will be increasingly phased out leaving renewables to play on the market independently, over the counter, or corporate PPAs can be an attractive tool for securing necessary financing outside of renewable energy auction schemes for the developers and for private companies as a way for decarbonising their energy needs. 


\subsubsection{Corporate Power Purchase Agreements (Corporate PPAs)}

Corporate PPA is one of the tools increasingly used by private companies to decarbonise their energy demand, meet sustainability objectives while satisfying investors and the general public's pressure. As of mid-2019, three of the most significant platforms gathering private corporations that announced their sustainable commitments (TCFD, the RE100 and the science-based targets platform) reached 1400 members, of which majority joined post-2016. This level of engagement demonstrates a keen interest in the private sector in decarbonisation efforts and options to do so. In 2018, estimated $14 \mathrm{GW}$ of renewable capacity was signed by the private sector under corporate PPAs, bringing the global total to $33 \mathrm{GW}$. The first three quarters of 2019 resulted in deals equivalent to $9 \mathrm{GW}$ renewable capacity (BNEF 2019a).

A power purchase agreement is essentially a contract between two parties where one party sells both electricity and renewable energy certificates that might be a secondary product to the electricity generated to another party. In a corporate PPA, the seller is most often a renewable energy project developer or project owner. The buyer, or the offtaker, is a corporate or industrial entity with significant energy needs. The corporate PPAs can take two forms: physical or financial, often referred to as 'virtual'.

In a physical corporate PPA, the seller develops, owns and operates the renewable energy project and is responsible for delivering contracted power to the seller up to the delivery point. The offtaker buys the electricity directly from the seller. The offtaker takes ownership of the electricity from the delivery point as well as any corresponding renewable energy certificates and is responsible for moving bought electricity from the generator to its load.

The virtual corporate PPA (VPPA) is a financial contract rather than a contract for power purchase. In this type of contract, the offtaker buys the project's output and associated renewable energy certificates at a fixed price. The generator sells electricity on the market and passes the revenue collected to the offtaker. On the other hand, the offtaker agrees to pay the seller a fixed price, agreed upon in the signed PPA, for the renewable generation that developer sold to the grid. The fixed rate signed in the contract is the guaranteed price that the developer is to receive for generated power, irrespective of the ever-changing market price. When the market price exceeds the fixed contracted price, the developer passes the positive difference to the offtaker. When the market price is below the contracted price, the offtaker must pay the developer the difference (RE-Source 2019). This type of contract is often referred to as a contract for difference (CfD). The VPPA guarantees the seller a fixed price for generated and sold electricity, helping them in obtaining affordable financing to cover the initial investment costs. As a result, the VPPA can help commissioning of new renewable projects that would otherwise not be constructed. The VPPA resulting in a new capacity built can be particularly attractive to commercial offtakers that aim to decarbonise their demand and have electricity supply widely dispersed (Penndorf 2018).

The corporate PPAs are complex contracts bearing advantages and risks to both parties. Advantages to the seller are numerous, starting from guaranteed offtaker 
for electricity generated at a fixed price agreed for a long time durations. Increased creditworthiness can help to secure affordable financing, making the project economically viable resulting in new business for the developer. Benefits for the offtaker are long-term price stability, the company's budget stability, decarbonisation of energy demand and possible influence over renewable energy project specs and site.

Several risks are common for both the developer and the offtakes. Corporate PPAs have higher administrative costs. Possible regulatory changes rendering further contract execution impossible or at an increased cost are an essential risk factor to be accounted for by both parties and accommodated for upfront. In addition, in the case of long-term market distortion, the agreement has to be flexible enough to permit post-signature adjustments.

Corporate PPAs require the existence of certain regulatory and market conditions. These types of contracts are possible in countries with organised liberalised electricity markets where independent developers are allowed to build, own, operate and sell electricity to the grid or another party at its liberty with either regional transmission operator or an independent system operator in place. Additionally, signing corporate PPAs makes the most sense in countries where renewable energy policy support is minimal, evolves towards full market integration, or is to be increasingly phased out. In these conditions, developers are required to seek other streams of revenues and financing outside of administratively set prices or auction systems. For the offtakers, signing corporate PPAs requires a profound understanding of the electricity market, market trends and understanding of price evolutions over a short to mid-term (BNEF 2019b).

Thus far, the corporate PPAs predominantly developed in the United States of America, where the developers could rely mostly only on renewable support in the form of a tax exemption (the Production Tax Credit). However, as renewable energy measures in Europe are becoming limited or being phased out, corporate PPAs are becoming an increasingly attractive option for both developers and corporate entities. Corporate PPAs in Europe are more common in Nordic countries with several projects also signed in the United Kingdom, France and Denmark. Recently, developers and investors started to show interest in opportunities in Poland with two contracts signed so far by Mercedes-Benz and Grupa Azoty, amounting to $50 \mathrm{MW}$ of renewable capacity together (Grupa Azoty 2019; WindEurope 2018). However, it is anticipated that going forward, more corporate PPAs will be signed in Poland as prices for baseload electricity are increasing rapidly and with estimations of further growth over the short-term period. This growth is mostly driven by increasing prices of the EU emissions trading system (ETS) auctions to which Poland is very susceptible as country's power generation is based on lignite coal (BNEF 2019c).

\subsubsection{Policies for Self-consumption and Distributed Generation}

The story of renewables for power generation is not only a story of large-scale installation previously driven by fixed feed-in tariffs and nowadays by auction systems or corporate PPAs going forward. In 2018, around $42 \%$ (or $210 \mathrm{GW}$ ) of the total installed 
solar PV capacity was coming from smaller (less than 1 MW capacity size) projects for commercial, residential and off-grid installations. For a long time, distributed PV projects were not cost-competitive with large-utility scale power plants. However, with the costs of PV dropping significantly over the last decade and expanding policy support in Europe and increasingly so in other regions across the globe, jump-started an important growth of distributed solar PV to the status we observe today. Currently, majority of the distributed solar PV capacity is located in Europe. Government policies, incentives and regulations have been central to this deployment in Europe and globally.

As indicated above, large portion of countries have renewable energy targets, which often include solar PV capacity objectives. However, several important markets have a specific distributed solar PV targets such as China (60 GW by 2020) or India (40 GW of rooftop PV by 2022). Targets alone often do not determine the deployment. The policies adopted along the target, at least until today, determined the deployment speed and capacity growth volume.

Similarly as in case of large-scale projects, distributed PV installations can benefit from policies decreasing investment costs. To repeat, these are grants, rates, various tax benefits and tax exemptions. According to the IEA classification, there are three main policy models targeting consumption and sale of electricity from the distributed solar PV. These are:

\section{1. buy-all, sell-all model; \\ 2. net metreing system and \\ 3. real-time self-consumption models.}

In the first model, all solar PV generation is contracted to be sold directly to the utility. Usually, the electricity is sold at a fixed tariff rate for the duration of the contract similar as FIT system. However, in some countries, auctions are used as a price-finding and contract awarding mechanism for commercial installations (e.g.: France). Often, a feed-in tariff mechanism is used as well.

In this model, the installation owners still source all their electricity from the grid. Their activity as generator is separated from their needs as customers. In order for this model to be functional, the private entity is obligated to have two metres installed. One to measure electricity generated and send to the grid, and one to measure electricity sourced from the network.

In the net metreing model, the PV owners are enabled to consume electricity generated by their installation reducing consumption from the network. The excess of the electricity is sent to the grid in return for an energy credit. Accumulated credit can be used to decrease future electricity bill accrued by electricity consumption at another time from the network. The duration of the validity of the credit is determined by the scheme in which the prosumer is participating. Usually, the validity period ranges from 6 months to one year. However, it is possible for this period to be longer. Recently, in Poland, the validity of the credit was extended from one to two years. The duration of the validity period strongly influences the economic attractiveness of the net metreing scheme for the PV investor as the output of the installation varies 
largely through a day and seasons. Installation of one bidirectional metre is required for this model to be possible on the owner side.

In the real-time self-consumption model, the PV owner is allowed to generate, self-consume and sell excess of the electricity produced to the network. The difference from the net metreing system is that the accounting of electricity procurement from the network and sending off the excess happens within short time intervals (hourly or less than hourly time spans). Each unity of the electricity sent to the network is paid for with a price level determined by the utility with which the contract is signed. Often, the price is based on the wholesale or retail electricity price. Similarly as in case of the net metreing model, installation of one bidirectional model is required.

Self-consumption policies continue to evolve and countries are working on tailoring them to their needs and particular conditions. In order to cap costs of the selfconsumption policies, often additional limits and eligibility conditions are added. These can be put on a size of the installation eligible to participate in the scheme or on the amount of electricity sent to the network.

Other, less common self-consumption and electricity sell models exist where countries try to put a value of PV generation based on avoided large-scale generation capacity expansions, fuel expenditures or on benefits brought to the system or a society such as grid integration costs, $\mathrm{CO}_{2}$ reduction or job creation.

The economic attractiveness of the participation in the above models is determined by several main factors. In the all abovementioned options, duration of the contract signed with the utility is pivotal. Additionally, in the buy-all, sell-all model, the LCOE is impacted by the contracted tariff level. In the remaining models length of the energy accounting period, remuneration type and price of excess generation and evolution of electricity retail tariff determine the attractiveness of the distributed PV project.

\subsection{Renewable Heat and Transport Policies}

The heating and cooling sector is complex and fragmented, and generally less well understood than the electricity sector. Its complexity makes effective policymaking challenging. Different thermal demand patterns in buildings (depending on climate, buildings efficiency, technology, occupancy purpose and others), and a multitude of technologies and fuel options availability on the supply side for water and space heating contribute to the complexity of the sector. Manufacturers range from large, multi-national corporations to small, local installers using different solutions. Additionally, different solutions are implemented across countries but also on regional and city-levels, which means that different institutions are responsible for policies and regulations-making. Due to this complexity, renewable energy policy adoption is more difficult and visibly lags behind in comparison to policy saturation in the renewable electricity sector. 
In 2010, 13 countries, mostly in Europe and Latin America, had renewable heat mandates in place. By 2017 mandates spread to 22 countries across all regions, with Europe still leading, driven by the EU 2020 targets. Outside of mandates, almost 35 countries had some form of a capital grant in place facilitating purchase of the renewable heating equipment (IEA 2018). While the number of countries with availability of soft loans and tax incentive are difficult to track, these policies remain pivotal for the sector's decarbonisation due to their direct impact on the investment costs.

Many policy tools used for support of renewables in electricity sector are adjustable and applicable to support renewables in the heating and cooling sector. These are in particular different forms of targets and obligations as well as a range of measures affecting upfront investments costs. Heating and cooling sector is an area where policies for renewable energy and energy efficiency converge as many financial and fiscal forms of support for renewable heat technologies are embedded in the energy efficiency policies, programmes and standards.

Policies to support the use of renewables in heat can take a variety of forms, from mandates to heat generation incentives, from additional taxation to the ban of use of certain forms of energy. Mandates are the most commonly used type of policy, often requiring targeted types of buildings to satisfy a part of the heat demand needs through renewable energy (such as bioenergy or solar water heaters). The rate of implementation remains, though, more effective for newbuilds than for refurbishments, given the slow pace of the latter, due to the long lifetime of buildings.

District heating producers can benefit from incentives based on the amount of heat generated. This type of policy is very similar to feed-in-tariffs used in the power sector, providing a certainty of cashflow over a predetermined span of time. This form of policy support is still not widely spread; an example of a successful renewable heat generation-based policy is the Renewable Heat Incentive available in the UK since 2011 and currently scheduled for closure in the early 2021.

Countries can also adopt indirect forms of support for renewable heat. These are in particular carbon or additional tax obligations put on owners that generate heat using fossil fuels (wood and various coal products). These indirect measures provide important price signals, however design and implementation challenges remain, especially in contexts where energy-intensive industries are subject to strong international competition and may ask for exemptions.

Countries also have in their disposal introduction of bans on fossil fuel heating options. Bans can be very effective provided other suitable heat alternatives exist and are accessible to investors of various heat demand patterns and quotas. The effectiveness of bans heavily relies on monitoring and enforcement of such measures.

Renewables in transport take a form of biofuels, primarily used in road transport but increasingly applied in rail, shipping and aviation. The most common form of the support for biofuels in transportation is well spread biofuel blending mandates, often accompanied by fiscal incentives (IEA 2011). In 2018, around 80 countries had some form of a blending mandate. However, majority of these mandates required low blending levels (less than 10\%) (IEA 2018) with few exceptions of Brazil (ethanol $18 \%$ blending mandate in 2019 cut from 27\%), Paraguay (ethanol 25\% mandate) 
and Indonesia (biodiesel 15\%.mandate) (BiofuelsDigest 2019). Countries often provide tax waivers or tax cuts on biofuels production, distribution and consumption. Governments start to adopt sustainability mandates instead of blending mandates. The sustainability criteria are set based on avoided greenhouse gas emissions in comparison to conventional fuels.

\section{Energy Efficiency}

\subsection{Energy Efficiency Policy Classification}

Improvements in the energy efficiency can be the most cost-effective strategy to reduce emissions associated with energy consumptions in all sectors globally. However, various barriers such as financial, institutional, technical or lack of awareness often slow down the energy efficiency uptake. The energy efficiency policies and measures aim to overcome these barriers and as in the case of renewables support, blend of policies can be used in parallel in order to achieve energy efficiency gains in various sectors. Policies and tools can be implemented on regional, national, state or city-levels targeting appliances, equipment, improvements in buildings and vehicles in the end-use sector.

The IEA in its recent Energy Efficiency Market Report (IEA 2019a) groups the energy efficiency policies in three large categories:

\section{(1) mandatory policies}

(2) energy efficiency,obligations and

(3) fiscal or financial policies.

Outside of this main categorisation governments adopt other types of policies and programmes such as information provision, installers training and capacity programmes. Increasingly, private sector and various corporations adopt voluntary objectives and programmes to decrease the energy demand and improve efficiency.

\subsubsection{Mandatory Energy Efficiency Policies Setting Performance Requirements and Standards}

The first policy category, the mandatory policies and regulations set minimum energy efficiency performance requirements. Forms of such requirements are used extensively since the 1970 s.

This category includes mandatory minimum energy performance standards (MEPS) for appliances and equipment, mandatory building codes, fuel economy standards and targets for industry. The MEPS for appliances is widely adopted and is considered an effective tool to improve the energy efficiency improvements in the 
end-use sector and reduce $\mathrm{CO}_{2}$ emissions by banning the worst-performing appliances from the market, forcing manufacturers to innovate and improve their product. At the same time, they force customers to purchase more efficient appliances. The energy-efficient labels help the customers to make an informed choice but also provide educational value (Sonnenschein and van Buskirk 2019). In 2004, around 50 countries had these types of standards in place. By 2013, just over 80 countries used MEPS for energy efficiency improvements (IEA 2015).

The voluntary or mandatory building energy efficiency codes (BEECs) pertain specifically to the buildings sector and can be put on existing or newly build structures in the form of a standard. As buildings account for around $36 \%$ of global final energy use and nearly $40 \%$ of energy-related $\mathrm{CO}_{2}$ emissions in 2017 , the energy-saving opportunities, cuts in the $\mathrm{CO}_{2}$ emissions and in costs are substantial. Number of building codes implemented grown from 54 countries in 2010 to nearly 70 countries in 2018 (IEA and UNEP 2018). Energy gains in the buildings sector can be achieved through reducing energy wastage, usage of energy-efficient appliances, lightening, space heating and cooling as well as through using materials and designing buildings to minimise the energy use.

The BEECs are often categorised as either prescriptive or performance based depending on the choice of an approach chosen for a compliance with the standard. The prescriptive compliance approach is a regulation requiring usage of specific materials in the construction of the building. These standards require minimum thermal performance level of each building envelope component such as walls, roofs, windows and doors as well as minimum energy efficiency requirements for heating, ventilation, water heating and lighting systems. The insulation of the building envelope or the insulation of pipes and ducts are also specified in the code. The performance-based approach sets annual levels of building energy consumption covering space cooling and heating, lightening as well as water heating.

The BEECs can be adopted on the voluntary or mandatory basis. However, even if the standard is adopted in the form of a mandatory measure compliance and enforcement of the codes is a key challenge. Achieving full compliance with set codes ab extend in time. Building strong compliance infrastructure around construction and building sector facilitates enforcement of the adopted codes and standards. Compliance with adopted codes should be measured during four stages of building project. That is to check compliance at the design stage before issuing the permit, during the construction phase, before issuing occupancy permit and once the building is occupied to measure actual energy performance. These checks help fixing potential issues and deviations from standards while it is still possible to do so (IEA 2013).

Energy efficiency standards also exist for transport sector. These are transport fuel economy standards and can be applied to passenger as well as to light, large trucks or to heavy duty vehicles. In these standards the governments or responsible relevant country regulatory body sets a minimum fuel standard for each given vehicle model produced or sold within its jurisdiction that must be respected. These standards pertain to fuel consumed by a vehicle in respect to travelled distance. Often expressed in miles per USgallon (mpg). Goal of such standards is to push manufacturers to produce more fuel-efficient machines while continuously reducing $\mathrm{CO}_{2}$ emissions 
generated per usages of the vehicle. Standards also help to push out less efficient and more polluting cars or other types of automobiles from the market (US DOE 2019).

\subsubsection{Energy Efficiency Obligation Policies}

The second policy category, the energy efficiency obligation programmes are strongly established in the United States of America where are mostly known as the energy efficiency resource standards (EERS). These types of standards establish specific, long-term targets for energy savings to be met through energy efficiency measures. These standards play a role of a target, with a clear specification by whom the target is to be met. Obligation on meeting the standards are put on utility or nonutility administrators that are subsequently met through customer energy efficiency programmes. The standards can apply to electric or natural gas utilities adopted via legislation or secondary regulation (ACEEE 2019).

The standards do not indicate how the efficiency improvements are to be gained but indicate a minimum amount of savings to be reached. The obliged party has a flexibility of choosing how the requirement will be met giving the utility freedom of choice of the programme that would be the most effective for them. The objectives can be expressed in various units ranging from a percentage form (on electricity delivered) or in megawatt, gigawatt, or kilowatt-hours (ACEEE 2019). The EER standards are similar in their set up to the renewable energy portfolio standard (RPS). Often the EERS are of mandatory nature, they can be also established as a voluntary mechanism (C2ES 2019).

\subsubsection{Fiscal and Financial Policies Targeting Energy Efficiency}

Financial incentives. These include policies put in place to encourage the take-up of energy-efficient technologies and behaviour through financial or fiscal rewards, including grants and subsidies, tax relief, equity finance, loans and debt finance, guarantees, on-bill finance and other incentives (IEA 2019a). All this incentive types mirror fiscal and financial support mechanisms used for renewable energy solutions. Their main goal is to decrease level of capital investment bore by the investor.

\section{Nuclear Energy}

The deployment of nuclear energy power plants saw its peak during the 1970s and the first half of the 1980s, on the back of national programmes, in particular in the United States, in Canada, in several European countries, in Russia and Japan.

In the period 1965-1990, global nuclear-installed capacity increased 64-fold and, by 1990 , more than $90 \%$ of the global capacity was installed in these five regions. Over the following years the growth reduced drastically, with global capacity increasing 
by some $15 \%$ in 20 years (IAEA 2019), as a result of several factors, including the fears that followed the Chernobyl disaster, the saturation in some markets and the significant investment costs needs.

The most recent years, in particular following the Fukushima accident, saw the emergence of three major trends. On one side, some countries (e.g. Germany, Belgium and Switzerland) decided the gradual phase-out of nuclear energy from the power mix. On the other side, several emerging economies have decided to continue to pursue the deployment of nuclear power; China has been leading this trend over the last decade (and is expected to continue over the coming years), but several other countries have plans to expand or start new nuclear energy programmes. Thirdly, several countries with existing and ageing nuclear power fleet are facing the question mark if closing, extending the lifetime or replacing the existing assets (IEA 2019c).

Nuclear policies are therefore very varied according to the intentions and the direction decided in each country. Some countries see nuclear power as an important component for the decarbonisation of their power mix - and of the energy transition at large-while others see it as a no-way forward. In several cases, major decisions on the timing of phasing out, on the allowed maximum lifetime of the existing power plants and on the eventuality and the extent of new builds are spurring important national debates and have not yet been set.

Significant differences emerge across countries depending on if liberalised or regulated electricity power markets are in place, but it has become increasingly clear that the construction of new nuclear power plants based solely on market forces is not a viable option, in particular due to financial and regulatory risks. Several countries have therefore decided to put in place support mechanisms (such as the Contract for Difference in the United Kingdom, or the inclusion of nuclear within the Zero Emission Credit in some States of the USA), while many others support directly the construction of new nuclear power plants.

The investment costs can be very different across countries, with the highest costs seen in first-of-a-kind plants in mature economies (e.g. Europe and the United States) and the lowest costs in China, thanks in particular to a continuous stream of new builds and low construction, labour and material costs. Despite these differences, one element is common to almost all new nuclear power plants: the very high upfront investment cost. This is due to the high unit investment costs (usually in the order of 2500-6500 USD/kW) and the very large capacities of the main reactors built (usually in the order of 1000-1600 MW).

Policies aimed at reducing the related financing costs can therefore play a key role for the deployment of new plants, as well as policies that can optimise and reduce the building process and therefore reduce the long construction times (another key element for new nuclear plants). To solve or reduce some of these financing aspects, but also to open new market opportunities for smaller and more flexible use of nuclear power, several constructors are now exploring the possibility of building so-called small modular reactors (SMRs). These plants, usually of the size of 30-300 MW, are now in the demonstration phase and are attracting significant attention and support from several governments. 


\section{Carbon Capture, Utilisation and Storage (CCUS)}

Carbon capture, utilisation and storage (CCUS) is a technology that can provide a significant contribution to achieve a low-carbon-and in the long-run a zero-carbonenergy world. This technology has been applied in some industrial sectors for over two decades, and currently has almost 20 large-scale projects and several dozens of small-scale ones in operation. Looking ahead, it can play a significant role in the decarbonisation strategies of several sectors, ranging from enhanced oil recovery (EOR) to fossil-fuelled power generation (mainly coal, but also gas), from the production processes in heavy industry to the creation of so-called carbon sinks (e.g. bioenergy CCS or BECCS).

The importance of CCUS technology in the industry sector stems from the fact that the $\mathrm{CO}_{2}$ emissions in this sector, and in particular in the cement, iron and steel, and chemical subsectors, are among the most challenging to abate, as a significant portion of these emissions result from chemical or physical reactions and there is a limit scope for fuel switching away from fossil fuels in processes that require high-temperature heat. The scope for policy action is therefore relevant, requiring concerted actions between governments, industrial and financial actors (IEA 2019g).

The power sector has a more varied availability of low-carbon generation technologies, ranging from dispatchable renewables (such as hydropower and bioenergy) to non-dispatchable renewables (mainly wind and solar PV) and nuclear power. Nonetheless, two-thirds of current global electricity generation is fossil fuel based. Given the long lifetime of power assets, and the very young age of the coal fleet (in particular in China); it faces the mutual challenge of 'emissions lock-in' and of possible stranded assets. Retrofitting with CCUS technology represents therefore a very important option, in particular for some countries, to avoid stranded assets and to keep flexible capacity in the power systems (IEA 2019h).

While the CCUS technology is already a competitive decarbonisation option in some process (such as the production of ammonia), it still needs to achieve cost reductions and the scale needed in the long-term decarbonisation scenarios. As it is the case for most other low-carbon technologies, CCUS is characterised by high upfront investment costs. The technology had significant momentum globally in the second half of the first decade of 2000s, but then lost some grounds and slowed down in terms of demonstration projects in subsequent years, as actual public funding support did not match previous announcements (IEA 2016).

Adequate funding and support measures for R\&D and for demonstration projects are therefore key for a quick upscale of the technology. For the early phases, the policy options range from regulatory to financial, including grants, tax credits or low-carbon product incentives. In the longer run, $\mathrm{CO}_{2}$ pricing can provide an important long-term investment signal. Particular attention should be provided to the industrial sectors that face global competition, while for other sectors such as cement or power generation, a fair level playing field should be established at national or regional scale.

Additional areas for policy intervention are also represented by the development of $\mathrm{CO}_{2}$ transport and storage networks, the removal of regulatory and social barriers and 
obstacles to the deployment of the technology and removing uncertainties regarding the availability of storage. Increasing attention is also being given to the development of CCUS hubs, that can support new investment opportunities through economies of scale, and can be developed together with storage considerations (UK Government 2018).

\section{Conclusions}

Energy policies have been and continue to have a pivotal role in the energy transition triggering and fast-tracking renewables deployment, incentivising uptake of energy efficiency, supporting changes in the energy system and paving the role of CCUS and nuclear power in the energy mix of tomorrow.

Policies targeting renewables expanded fast over the last two decades, initially adopted by a small pool of countries with well-developed economies. Currently, nearly all countries across the globe have some form of a renewable energy policy in place effectively triggering high deployment levels and making solar PV and wind front-running green power technologies as cost continue to decrease and various market-entry barriers are tackled.

Over time, policies evolved growing in their complexity. Through increasing policymaking know-how, governments gained experience and skill in tailoring mechanisms to their needs and energy system specifications at decreasing costs. Policies with administratively set prices for renewable power generation triggered the renewables deployment. However, nowadays countries move away from these types of mechanisms moving towards policy frameworks that allow price setting through market competition.

Going forward, overall system integration in which all generators are able to secure sufficient level of revenues is to be in focus. Private sector is expected to play an important role in furthering decarbonisation of the energy system through greening their energy demand with help of corporate power purchase agreements becoming an active player in the energy domain.

Policies for energy transition go beyond renewables for power generation but support mechanisms are adaptable and can be applied to heating, cooling and transport sectors as well as in efforts aiming to decrease energy consumption through efficiency measures. Energy efficiency is a pivotal domain in the successful energy transition and often strongly interlinked with renewables and requires strong governments attention.

Role of nuclear energy in the energy transition depends on countries' energy strategies as we currently observe examples of states that decide to reduce (France) or eliminate (Germany) this source of energy, while others take their initial steps towards first reactors. According to World Nuclear Association, as of 2020 around 30 countries are either considering, planning or launching their nuclear power programmes. UAE, Belarus, Bangladesh and Turkey are currently working on the construction of their reactors (World Nuclear Association 2020). The CCUS provides 
important opportunities in achieving deep decarbonisation level with several proven projects in operation. However, in case of both technologies, strategy making, target setting and policymaking are indispensable to tackle high upfront costs.

Going forward, energy policies will continue to be at the heart of energy transition continuously evolving and adapting to countries needs and changing market realities.

\section{References}

ACEEE (American Council for Energy-Efficient Economy) (2019) Energy Efficiency Resource Standard (EERS). https://aceee.org/topics/energy-efficiency-resource-standard-eers

BiofuelsDigest (2019) Biofuels mandates around the World 2019. https://www.biofuelsdigest.com/ bdigest/2019/01/01/biofuels-mandates-around-the-world-2019/

BNEF (Bloomberg New Energy Finance) (2019a) Corporate PPA Deal Tracker, BNEF, London

BNEF (2019b) A guide to corporate clean energy procurement, BNEF, London

BNEF (2019c) 2 h 2019 Corporate energy market outlook, BNEF, London

C2ES (Center for Climate and Emergy Solutions) (2019) Energy efficiency standards and targets. https://www.c2es.org/document/energy-efficiency-standards-and-targets/

UK Government (2018) Policy paper: the UK carbon capture, usage and storage (CCUS) deployment pathway: an action plan, London. https://www.gov.uk/government/publications/the-uk-carboncapture-usage-and-storage-ccus-deployment-pathway-an-action-plan

Grupa Azoty (2019) PGE Energia Odnawialna zbuduje z Grupa Azoty Siarkopol farmę fotowoltaiczną. www.grupaazoty.com/pl/wydarzenia/pge-energia-odnawialna-zbuduje-z-grupaazoty-siarkopol-farme-fotowoltaiczna.html

IAEA (International Atomic Energy Agency) (2019) PRIS database, IAEA, Vienna. https://pris. iaea.org/

IEA (2011) Technology roadmap: biofuels for transport, IEA, Paris

IEA (2013) Modernising building energy codes, IEA, Paris

IEA (2015) Market report: energy efficiency 2015, IEA, Paris

IEA (2016) 20 years of carbon capture and storage, Paris

IEA (2018) Renewables 2018-analysis and forecast to 2023, IEA, Paris

IEA (2019b) How2Guide to solar technologies, IEA, Paris

IEA (2019c) Nuclear power in a clean energy system, IEA, Paris

IEA (2019d) Policies database, online database, IEA, Paris. www.iea.org/policies

IEA (2019e) Renewables 2019-analysis and forecast to 2024, IEA, Paris

IEA (2019f) Renewables auctions database, internal database, IEA, Paris

IEA (2019g) Transforming industry through CCUS, IEA, Paris

IEA (2019h) World energy outlook 2019, IEA, Paris

IEA (International Energy Agency) (2019a) Energy efficiency 2019, IEA, Paris

IEA and UNEP (United Nations Environment Programme) (2018) 2018 Global status report, IEA and UNEP, Paris

IRENA (International Renewable Energy Agency) (2015) Renewable energy target setting, IRENA, Abu Dhabi

IRENA, IEA and REN21 (2018) Renewable energy policies in a time of transition. https://www.irena.org/-/media/Files/IRENA/Agency/Publication/2018/Apr/IRENA_IEA_ REN21_Policies_2018.pdf

NREL (National Renewable Energy Laboratory) (2010) A policymaker's guide to feed-in tariff policy design, NREL, California

Penndorf S (2018) Renewable energy power purchase agreements, 3Degrees, London. https:// 3degreesinc.com/latest/ppas-power-purchase-agreements/ 
RE-Source (2019) Introduction to corporate sourcing of renewable electricity in Europe, Re-Source. http://resource-platform.eu/toolkit/

Sonnenschein J, van Buskirk R (2019) Minimum energy performance standards for the $1.5{ }^{\circ} \mathrm{C}$ target: an effective complement to carbon pricing. J Energy Effic 12:387-402. https://doi.org/10. 1007/s12053-018-9669

US DOE (U.S Department of Energy) (2019) Vehicle fuel economy and greenhouse gas (GHG) emissions standards. https://afdc.energy.gov/laws/385

WindEurope (2018) First polish PPA is also Europe's first automotive renewables deal. https:// windeurope.org/newsroom/press-releases/first-polish-ppa-is-also-europes-first-automotiverenewables-deal/

World Nuclear Association (2020) Emerging Nuclear Energy Countries. https://www.worldnuclear.org/information-library/country-profiles/others/emerging-nuclear-energy-countries.

aspx

Open Access This chapter is licensed under the terms of the Creative Commons Attribution 4.0 International License (http://creativecommons.org/licenses/by/4.0/), which permits use, sharing, adaptation, distribution and reproduction in any medium or format, as long as you give appropriate credit to the original author(s) and the source, provide a link to the Creative Commons license and indicate if changes were made.

The images or other third party material in this chapter are included in the chapter's Creative Commons license, unless indicated otherwise in a credit line to the material. If material is not included in the chapter's Creative Commons license and your intended use is not permitted by statutory regulation or exceeds the permitted use, you will need to obtain permission directly from the copyright holder. 